\title{
Dietary oxidised frying oil causes oxidative damage of pancreatic islets and impairment of insulin secretion, effects associated with vitamin E deficiency
}

\author{
Ya-Fan Chiang ${ }^{1} \dagger$, Huey-Mei Shaw ${ }^{2} \dagger$, Mei-Fang Yang $^{3}$, Chih-Yang Huang ${ }^{4}$, Cheng-Hsien Hsieh ${ }^{1}$ \\ and Pei-Min $\mathrm{Chao}^{1 *}$ \\ ${ }^{1}$ Institute of Nutrition, China Medical University, Taichung 404, Taiwan, ROC \\ ${ }^{2}$ Department of Health and Nutrition, Chia-Nan University of Pharmacy and Science, Tainan 717, Taiwan, ROC \\ ${ }^{3}$ Department of Anatomy, China Medical University, Taichung 404, Taiwan, ROC \\ ${ }^{4}$ Graduate Institute of Basic Medical Science, China Medical University, Taichung 404, Taiwan, ROC
}

(Received 17 August 2010 - Revised 15 October 2010 - Accepted 25 October 2010 - First published online 16 December 2010)

\section{Abstract}

We previously reported that, in rodents, a diet with a high oxidised frying oil (OFO) content leads to glucose intolerance associated with a reduction in insulin secretion. The present study aimed at investigating the impairment of pancreatic islets caused by dietary OFO. C57BL/6J mice were divided into three groups to receive a low-fat basal diet containing $5 \mathrm{~g} / 100 \mathrm{~g}$ of fresh soyabean oil (LF group) or a high-fat diet containing $20 \mathrm{~g} / 100 \mathrm{~g}$ of either fresh soyabean oil (HF group) or OFO (HO group). After 8 weeks, mice in the HO group showed glucose intolerance and hypoinsulinaemia, and their islets showed impaired glucose-stimulated insulin secretion $(P<0 \cdot 05$; HO group $v$. LF and HF groups). Significantly higher oxidative stress and a lower mitochondrial membrane potential were observed in the islets in the HO group compared with the LF and HF groups. Immunoblots showed that the reduction in insulin levels in HO islets was associated with activation of the c-Jun $\mathrm{NH}_{2}$-terminal kinase and a reduction in levels of pancreatic and duodenal homeobox factor-1. In a second study, when dietary OFO-induced tissue vitamin E depletion was prevented by large-dose vitamin E supplementation ( $500 \mathrm{IU}(1.06 \mathrm{mmol}$ all-rac- $\alpha$-tocopherol acetate) $/ \mathrm{kg}$ diet; $\mathrm{HO}+\mathrm{E}$ group), the OFO-mediated reduction in islet size and impairment of glucose tolerance and insulin secretion were significantly attenuated $(P<0.05$; HO group $v$. HO $+\mathrm{E}$ group). We conclude that a high level of dietary OFO ingestion impairs glucose metabolism by causing oxidative damage and compromising insulin secretion in pancreatic islets, and that these effects can be prevented by vitamin E supplementation.

Key words: Oxidised frying oil: Glucose-stimulated insulin secretion: Vitamin E: Pancreatic and duodenal homeobox factor-1: c-Jun $\mathrm{NH}_{2}$-terminal kinase

Deep-frying is a common cooking practice, and the safety of oxidised frying oil (OFO) ingested with fried food is a concern. During the deep-frying process, a series of reactions, including auto-oxidation, thermal oxidation, polymerisation, cyclisation and fission, occur in the frying oil ${ }^{(1)}$. Generally, OFO prepared using normal cooking practices as part of a nutritionally balanced diet is regarded as safe due to the induction of detoxifying cytochrome P450 enzymes and the limited absorption of toxic polymers produced during the deep-frying process ${ }^{(2,3)}$. However, animal studies have revealed that some nutritional and metabolic effects related to $\mathrm{OFO}$ ingestion are noteworthy.
$\mathrm{We}^{(4-6)}$ and others ${ }^{(7,8)}$ have shown that, in rats and mice, OFO ingestion can influence lipid metabolism through the activation of PPAR $\alpha$ in the liver, leading to increased fatty acid catabolism. Paradoxically, impairment of glucose metabolism, i.e. glucose intolerance, is observed in OFO-fed rodents $^{(9)}$. When OFO-induced effects were compared with conjugated linoleic acid-induced lipodystrophic diabetes in mice, we found that, although both are characterised by body fat loss and glucose intolerance, OFO-mediated glucose intolerance is due to insufficiency of insulin secretion, compared with hyperinsulinaemia and insulin resistance caused by dietary conjugated linoleic acid ${ }^{(10)}$.

Abbreviations: GPx, glutathione peroxidase; GSIS, glucose-stimulated insulin secretion; HBSS, Hanks' balanced salt solution; JC-1, 5,5',6,6'-tetrachloro$1,1^{\prime}, 3,3^{\prime}$-tetraethylbenzimidazolocarbocyanine iodide; JNK, c-Jun $\mathrm{NH}_{2}$-terminal kinase; LPO, lipid hydroperoxide; OFO, oxidised frying oil; PDX1, pancreatic and duodenal homeobox factor-1; ROS, reactive oxygen species; RPMI, Roswell Park Memorial Institute.

* Corresponding author: P.-M. Chao, fax +886 422062891 , email pmchao@mail.cmu.edu.tw

† These authors contributed equally to the present study. 
It has been reported that dietary OFO compromises vitamin E retention in many tissues, and that this can be attributed to a lower vitamin $\mathrm{E}$ intake and absorption and a faster catabolism/ turnover $^{(11-13)}$. Due to their relatively low expression of antioxidant enzymes, such as catalase and glutathione peroxidase (GPx), pancreatic $\beta$-cells are rather vulnerable to oxidative damage $^{(14,15)}$. Several lines of evidence have implicated reactive oxygen species (ROS) in the progression of $\beta$-cell dysfunction $^{(16-20)}$. Thus, although vitamin $\mathrm{E}$ content and free-radical scavenging systems in the pancreatic islets of OFO-fed mice have never been studied, it is conceivable that the reduced ability to secrete insulin caused by dietary $\mathrm{OFO}$ is associated with vitamin E deficiency and oxidative deterioration of pancreatic $\beta$-cells.

Pancreatic and duodenal homeobox factor-1 (PDX1), a transcription factor, plays a pivotal role in pancreatic $\beta$-cell differentiation and in insulin gene expression ${ }^{(21)}$. The DNAbinding activity of PDX1 is sensitive to glycation and the resulting oxidative stress ${ }^{(22)}$. Since PDX1 DNA-binding activity under oxidative stress conditions is preserved or decreased, respectively, by the overexpression of dominant negativec-Jun $\mathrm{NH}_{2}$-terminal kinase (JNK) or wild-type $\mathrm{JNK}^{(23)}$ and since dominant negative-JNK inhibits oxidative stress-induced PDX1 nucleocytoplasmic translocation ${ }^{(24)}$, it has been postulated that the JNK-mediated suppression of PDX1 DNA-binding activity accounts for some of the suppression of insulin gene transcription and of $\beta$-cell function related to oxidative stress $^{(25)}$.

In the present study, we hypothesised that the OFOinduced impairment of glucose tolerance and insulin secretion is due to the oxidative damage of pancreatic islets, which is associated with vitamin E deficiency. We first examined the free-radical scavenging ability and ROS levels of islets from mice fed fresh soyabean oil or OFO and the involvement of JNK-PDX1 signalling in the reduction in insulin production in OFO-fed mice. Subsequently, we tested whether the adverse outcome in glucose metabolism associated with $\mathrm{OFO}$ ingestion could be prevented by vitamin $\mathrm{E}$ supplementation.

\section{Materials and methods}

\section{Animals and diets}

Male C57BL/6J mice (7-week-old) were purchased from the Laboratory Animal Center of the National Science Council, Taipei, Taiwan, ROC. After acclimatisation to a standard rodent chow diet for 1 week, the mice were divided into three groups to receive, for 8 weeks, a low-fat basal diet containing $4 \mathrm{~g} / 100 \mathrm{~g}$ of fresh soyabean oil (LF group) or a high-fat diet containing $20 \mathrm{~g} / 100 \mathrm{~g}$ of either fresh soyabean oil (HF group) or OFO (HO group). In a subsequent experiment, the $\mathrm{HF}, \mathrm{HO}$ and $\mathrm{HO}+\mathrm{E}$ groups were set up, with $\mathrm{HF}$ and $\mathrm{HO}$ as before and the $\mathrm{HO}+\mathrm{E}$ group receiving the $\mathrm{HO}$ diet plus $\alpha$-tocopherol acetate supplementation (500 IU(1.06 mmol all-rac- $\alpha$-tocopherol acetate) $/ \mathrm{kg}$ diet), again for 8 weeks. Since the OFO-containing diet resulted in a significant reduction in food intake, the LF and HF groups were isoenergically pair-fed with the $\mathrm{HO}($ or $\mathrm{HO}+\mathrm{E})$ group. All animals were housed individually in stainless-steel wire cages in a room maintained at $23 \pm 2{ }^{\circ} \mathrm{C}$, with a controlled $12 \mathrm{~h}$ light $-12 \mathrm{~h}$ dark cycle and free access to tap water. The protocols for animal care and handling were approved by the Institutional Animal Care and Use Committee of the China Medical University.

The OFO was prepared by frying dough sheets in soyabean oil (President, Tainan, Taiwan, ROC) at $205 \pm 5^{\circ} \mathrm{C}$ for four $6 \mathrm{~h}$ periods, as described previously ${ }^{(4-6,9,10)}$. The extent of oxidation was evaluated by the acid value $(1.413 v .0 .034 \mathrm{mg} / \mathrm{g}$ $\mathrm{KOH}$ for OFO and fresh soyabean oil, respectively) and the conjugated diene levels (4592 v. $618 \mathrm{OD}_{233}$ units/g for OFO and fresh soyabean oil, respectively). The values were very similar to those obtained in our previous studies ${ }^{(4,9,10)}$. The compositions of the four test diets are shown in Table 1, the amounts of casein and the vitamin and mineral mixtures in the high-fat diets being adjusted to ensure that the four diets had an equivalent nutrient:energy ratio. The calculated vitamin E content (including dietary oil, vitamin mixture and supplement) of the four test diets is also shown in Table 1.

\section{Oral glucose tolerance test}

For the oral glucose tolerance test, the mice were fasted overnight, then tail blood was collected before $(0 \mathrm{~min})$ and at 30 , 60,90 and $120 \mathrm{~min}$ after oral administration of a $2 \cdot 5 \mathrm{M}$-glucose solution ( $1.5 \mathrm{~g} / \mathrm{kg}$ body weight), and whole blood glucose was measured using a MediSense Optium glucometer (Abbott Laboratories, Worcester, MA, USA).

\section{Preparation of mouse pancreatic islets}

Islets were isolated by modification of the methods of Lacy \& Kostianovsky $^{(26)}$ and Gotoh et al. ${ }^{(27)}$. In brief, fasting mice were anaesthetised under diethyl ether and the abdomen was opened, and the common bile duct was tied at its entrance to the duodenum. The duct was then cannulated, and $2 \mathrm{ml}$ of a collagenase solution $(1.2 \mathrm{mg} / \mathrm{ml})$ was injected to distend the pancreas, which was then immediately dissected, put into a plastic tube and incubated at $37^{\circ} \mathrm{C}$ for 15-25 min. After dispersing the digested materials, the reaction was stopped by the addition of $15 \mathrm{ml}$ of cold Hanks' balanced salt solution (HBSS), the tube was centrifuged at $125 \mathrm{~g}$ for $3 \mathrm{~min}$, and the pellet was washed gently three times with cold HBSs. The pellet was then suspended in Roswell Park Memorial Institute (RPMI)-1640 medium (Sigma-Aldrich, St Louis, MO, USA) and passed through a $500 \mu \mathrm{m}$ mesh filter to remove large undigested particles. Then, the filtrate was overlaid on top of $5 \mathrm{ml}$ of Histopaque and centrifuged at $200 \boldsymbol{g}$ for $25 \mathrm{~min}$. The islets at the interface were collected and washed three times with cold HBSS.

\section{Measurement of glucose-stimulated insulin secretion}

Freshly isolated islets were incubated in RPMI-1640 medium containing $2.5 \mathrm{~mm}$-glucose in $5 \% \mathrm{CO}_{2}$ at $37^{\circ} \mathrm{C}$ for $24 \mathrm{~h}$ to recover. To measure glucose-stimulated insulin secretion 
Table 1. Composition of the test diets

\begin{tabular}{|c|c|c|c|c|}
\hline & LF & $\mathrm{HF}$ & $\mathrm{HO}$ & $\mathrm{HO}+\mathrm{E}$ \\
\hline Maize starch (g/kg) & $620 \cdot 7$ & $414 \cdot 7$ & $414 \cdot 7$ & $414 \cdot 7$ \\
\hline Sucrose $(\mathrm{g} / \mathrm{kg})$ & 100 & 100 & 100 & 100 \\
\hline Casein $(\mathrm{g} / \mathrm{kg})$ & 140 & 167 & 167 & 167 \\
\hline Oxidised frying oil $(\mathrm{g} / \mathrm{kg})^{\star} \dagger$ & - & - & 200 & 200 \\
\hline Fresh soyabean oil $(\mathrm{g} / \mathrm{kg}) \dagger$ & 40 & 200 & - & - \\
\hline Cellulose (g/kg) & 50 & 60 & 60 & 60 \\
\hline Mineral mixture (AIN-93) (g/kg) & 35 & 42 & 42 & 42 \\
\hline Vitamin mixture (AIN-93M) $(\mathrm{g} / \mathrm{kg}) \ddagger$ & 10 & 12 & 12 & 12 \\
\hline L-Cystine (g/kg) & $1 \cdot 8$ & $1 \cdot 8$ & $1 \cdot 8$ & $1 \cdot 8$ \\
\hline Choline bitartrate $(\mathrm{g} / \mathrm{kg})$ & $2 \cdot 5$ & $2 \cdot 5$ & 2.5 & $2 \cdot 5$ \\
\hline tert-Butylhydroquinone (g/kg) & 0.008 & 0.008 & 0.008 & 0.008 \\
\hline All-rac- $\alpha$-tocopherol acetate $(\mathrm{IU} / \mathrm{kg}) \S$ & - & - & - & 500 \\
\hline Energy density (MJ/kg) & 16 & 19 & 19 & 19 \\
\hline Protein:energy (g/MJ) & 8.7 & 8.7 & $8 \cdot 7$ & $8 \cdot 7$ \\
\hline Mineral:energy (g/MJ) & $2 \cdot 2$ & $2 \cdot 2$ & $2 \cdot 2$ & $2 \cdot 2$ \\
\hline Vitamin:energy (g/MJ) & 0.63 & 0.63 & 0.63 & 0.63 \\
\hline \multicolumn{5}{|l|}{ Calculated vitamin $\mathrm{E}$ content } \\
\hline IU/kg\| & 80 & 116 & 99 & 599 \\
\hline IU/MJ & 5.0 & $6 \cdot 1$ & $5 \cdot 2$ & 31.5 \\
\hline
\end{tabular}

LF, low-fat basal diet containing $5 \mathrm{~g} / 100 \mathrm{~g}$ of fresh soyabean oil; HF, high-fat diet containing $20 \mathrm{~g} / 100 \mathrm{~g}$ of fresh soyabean oil; $\mathrm{HO}$, high-fat diet containing $20 \mathrm{~g} / 100 \mathrm{~g}$ of oxidised frying oil; $\mathrm{HO}+\mathrm{E}$, high-fat diet containing or oxidised frying oil with vitamin $\mathrm{E}$ supplementation.

* Oxidised frying oil was prepared by frying dough sheets in soyabean oil (President Company, Tainan, Taiwan, $\mathrm{ROC}$ ) at $205 \pm 5^{\circ} \mathrm{C}$ for $24 \mathrm{~h}$.

$\dagger \gamma$-Tocopherol levels in fresh soyabean oil and oxidised frying oil are 187 and $43 \mu \mathrm{g} / \mathrm{g}$, respectively. $\alpha$-Tocopherol levels in fresh soyabean oil and oxidised frying oil are 69 and $26 \mu \mathrm{g} / \mathrm{g}$, respectively.

$\ddagger$ Vitamin mixture contains $7.5 \mathrm{mg} / \mathrm{g}$ of all-rac- $\alpha$-tocopherol acetate ${ }^{(35)}$.

$\S 1 \mathrm{IU}=1 \mathrm{mg}$ all-rac- $\alpha$-tocopherol acetate.

\|I Includes $\gamma$ - and $\alpha$-tocopherol in fresh soyabean oil or oxidised frying oil plus all-rac- $\alpha$-tocopherol acetate in the AIN 93 vitamin mixture and the supplement. $1 \mathrm{mg}$ of $\alpha$-tocopherol $=1.49 \mathrm{IU}$; the biological function of $\gamma$-tocopherol is only 0.1 of that of $\alpha$-tocopherol ${ }^{(33)}$.

(GSIS), three sets of thirty islets from the same mouse were incubated for $30 \mathrm{~min}$ with $300 \mu \mathrm{l}$ of RPMI-1640 medium (number of mice tested in each group, 5). Since GSIS might be affected by islet size, islets of a similar size were picked under a microscope for the present study. After challenging with high glucose $(20 \mathrm{~mm})$ for $10 \mathrm{~min}$, the culture supernatants were collected to measure released insulin using an ELISA (Linco, St Charles, MO, USA).

\section{Biochemical analysis}

$\alpha$-Tocopherol concentration in the serum and liver and pancreas homogenates was analysed by HPLC as described previously ${ }^{(11,12)}$. Thiobarbituric acid-reactive substance levels in the liver homogenate were measured using the method of Oteiza et $a l .{ }^{(28)}$. To measure oxidative damage to the islets, total antioxidant ability, GPx activity and lipid hydroperoxide (LPO) levels in the isolated islets were measured using commercial kits (Cayman, Ann Arbor, MI, USA), according to the manufacturer's protocols.

The islet mitochondrial membrane potential $\left(\Delta \Psi_{\mathrm{m}}\right)$ was determined using a commercial kit, which uses 5,5',6,6'-tetrachloro-1,1',3,3'-tetraethylbenzimidazolocarbocyanine iodide (JC-1) as a mitochondrial membrane sensor (Sigma-Aldrich). JC-1 undergoes potential-dependent accumulation in mitochondria and shows a fluorescence emission shift from green (approximately $525 \mathrm{~nm}$ ) to red (approximately $595 \mathrm{~nm})^{(29)}$, which can be observed under a fluorescence microscope. ROS levels in islets were measured using $2^{\prime}, 7^{\prime}$-dichlorodihydrofluorescein diacetate (Sigma-Aldrich) ${ }^{(30)}$. Briefly, three sets of thirty islets freshly prepared from each mouse ( $n$ 5) were incubated with $800 \mu$ l of HBSS
(5 mm-glucose) containing $10 \mu \mathrm{M}-2^{\prime}, 7^{\prime}$-dichlorodihydrofluorescein diacetate for $30 \mathrm{~min}$ at $37^{\circ} \mathrm{C}$. Then, after three washes with HBSS, the islets were lysed by the addition of $200 \mu \mathrm{l}$ of deionised water and the supernatant was collected to quantify the fluorescence $\left(\lambda_{\mathrm{ex}} / \lambda_{\mathrm{em}}=485 / 528 \mathrm{~nm}\right)$.

\section{Protein electrophoresis and immunoblotting}

The islets were homogenised in radioimmunoprecipitation assay buffer (50 mm-Tris buffer, $\mathrm{pH} 7 \cdot 4$, containing $150 \mathrm{~mm}$ $\mathrm{NaCl}, 1$ mm-EDTA, $1 \%$ NP-40, 0.25\% sodium deoxycholate, $0 \cdot 1 \%$ SDS , $1 \%$ protease inhibitor cocktail and $1 \%$ phosphatase inhibitor cocktail (both from Sigma-Aldrich)). Then, the samples ( $40 \mu \mathrm{g}$ of protein) were subjected to electrophoresis on $10 \%$ SDS gels, transferred to a polyvinylidene fluorideplus transfer membrane (NEN Life Science, Boston, MA, USA) and immunoblotted. Primary antibodies used were rabbit antibodies against human insulin (Santa Cruz Biotechnology Inc., Santa Cruz, CA, USA), human phosphorJNK1 + JNK2 (Thr183 and Tyr185) (Cell Signaling, Danvers, MA, USA), human total JNK (Abcam, Cambridge, MA, USA), or mouse PDX1 (Chemicon, Billerica, MA, USA) or mouse antibody against Xenopus $\beta$-actin (Novus, Littleton, CO, USA). Horseradish peroxidase-labelled donkey anti-rabbit IgG or horseradish peroxidase-labelled goat anti-mouse IgG antibodies (Amersham International, Amersham, UK) were used as the secondary antibody. Bound antibodies were detected using an enhanced chemiluminescence Western blotting kit (Amersham International), and the images were quantified by densitometric analysis using a MultiImage Light Cabinet (Alpha Innotech Corporation, San Leandro, CA, USA). 


\section{Immunohistochemistry}

Islet morphology was studied by histological examination. Pancreas was fixed with $4 \%$ paraformaldehyde, dehydrated through a graded ethanol series, embedded in paraffin and cut into $2 \mu \mathrm{m}$ sections. Paraffin blocks were rehydrated with xylene, followed by decreasing concentrations of ethanol, permeabilised with $0.5 \%$ Triton X-100 in PBS for $5 \mathrm{~min}$ and blocked with $5 \%$ goat serum in PBS for $1 \mathrm{~h}$ at room temperature. Guinea-pig antibody against human insulin (Abcam) and Alexa Fluor 488-labelled goat anti-guinea pig IgG antibodies (Invitrogen, Carlsbad, CA, USA) were used as the primary and secondary antibodies, respectively. The $\beta$-cell area was measured by acquiring images at $200 \times$ with a fluoromicroscope equipped with a SPOT RT color-2000 digital camera (Diagnostic Instruments, Sterling Heights, MI, USA). Islet size was quantified in the area containing insulin-positive cells using SPOT Advanced software (Diagnostic Instruments).

\section{Statistical analysis}

Data are expressed as means with their standard errors for the eight mice per group (for GSIS and ROS, $n$ 5). The significance of differences between groups was analysed statistically by one-way ANOVA and Duncan's multiple range tests. Data were transformed to $\log$ values for the statistical analysis if the variances were not homogeneous. The general linear model of the Statistical Analysis Systems statistical software package (SAS Institute, Cary, NC, USA) was used for both statistical analyses, and differences were considered significant at $P<0 \cdot 05$.

\section{Results}

Since the animals were pair-fed isoenergically, there was no difference in energy intake between the LF, HF and $\mathrm{HO}$ groups (Table 2) or between the $\mathrm{HF}, \mathrm{HO}$ and $\mathrm{HO}+\mathrm{E}$ groups (data not shown). Dietary OFO-induced impairment of glucose tolerance and insulin secretion is shown in Table 2. Compared with the LF and HF groups, the HO group showed the highest area under the curve in the oral glucose tolerance test and the lowest fasting serum insulin levels and GSIS.

In accordance with previous studies on dietary OFO-compromised vitamin E status in tissues, resulting in a higher oxidative stress ${ }^{(10-12)}$, liver $\alpha$-tocopherol in the HO group was significantly lower, and thiobarbituric acid-reactive substances levels were significantly higher, than in the other two groups, with no difference between the LF and HF groups (Table 2). Since OFO-mediated vitamin $\mathrm{E}$ depletion and peroxidative stress in pancreatic islets have never been studied, total antioxidant ability, GPx activity and LPO content in islets were measured. As shown in Fig. 1(A), the HO group, but not the HF group, had a significantly lower total antioxidant ability than the LF group $(P<0 \cdot 05)$. When the HF and HO groups were compared, dietary $\mathrm{OFO}$ resulted in a significant reduction in GPx activity (Fig. 1(B)) and an increase in LPO content (Fig. 1(C)) in islets.

Next, we examined whether ROS levels increased in islets from the HO group and decreased the mitochondrial membrane potential, which is critical for insulin secretion ${ }^{(18)}$. As shown in Fig. 2(A), intracellular ROS production in islets was significantly higher in the HO group than in the HF and LF groups. Fig. 2(B) shows the fluorescence shift of the mitochondrial membrane potential sensor and that the HO-group islets fluoresced green, while the HF-group islets showed both yellow and green fluorescence, implying a lower mitochondrial membrane potential in the HO-group islets. This is in accordance with the notion that the mitochondrial membrane potential $\left(\Delta \Psi_{\mathrm{m}}\right)$ is positively correlated with $\mathrm{GSIS}^{(31)}$.

Since oxidative stress might down-regulate insulin expression through JNK activation and reduce levels of PDX1, which is needed for insulin gene transcription ${ }^{(23-25,32)}$, islet proteins were subjected to electrophoresis and immunoblotting. Fig. 3 shows a significant increase in phospho-JNK levels and a significant decrease in PDX1 and insulin levels

Table 2. Food (and energy) intake, antioxidant indices, glucose tolerance and insulin secretion of mice fed a low-fat basal diet containing $5 \mathrm{~g} / 100 \mathrm{~g}$ of fresh soyabean oil (LF group) or a high-fat diet containing $20 \mathrm{~g} / 100 \mathrm{~g}$ of either fresh soyabean oil (HF group) or OFO (HO group)

(Mean values with their standard errors)

\begin{tabular}{|c|c|c|c|c|c|c|}
\hline & \multicolumn{2}{|c|}{ LF } & \multicolumn{2}{|c|}{$\mathrm{HF}$} & \multicolumn{2}{|c|}{$\mathrm{HO}$} \\
\hline & Mean & SEM & Mean & SEM & Mean & SEM \\
\hline \multicolumn{7}{|l|}{ Feeding data } \\
\hline Food intake $(\mathrm{g} / \mathrm{d})$ & $4.57^{\mathrm{a}}$ & 0.14 & $3 \cdot 74^{b}$ & $0 \cdot 13$ & $3.83^{b}$ & $0 \cdot 1$ \\
\hline Energy intake $(\mathrm{kJ} / \mathrm{d})$ & 72 & 2 & 71 & 3 & 72 & 2 \\
\hline \multicolumn{7}{|l|}{ Antioxidant indices } \\
\hline Liver $\alpha$-tocopherol $(\mathrm{nmol} / \mathrm{g})$ & $82^{a}$ & 18 & $65^{\mathrm{a}}$ & 9 & $18^{\mathrm{b}}$ & 2 \\
\hline Liver TBARS $(\mathrm{nmol} / \mathrm{g})$ & $16^{\mathrm{b}}$ & 1 & $16^{\mathrm{b}}$ & 1 & $27^{a}$ & 3 \\
\hline \multicolumn{7}{|l|}{ Glucose tolerance and insulin secretion } \\
\hline AUC in the OGTT $\left(\mathrm{mmol} \times \mathrm{min} / \mathrm{l}^{*}\right.$ & $1073^{b}$ & 46 & $1048^{b}$ & 58 & $1310^{\mathrm{a}}$ & 48 \\
\hline Fasting serum insulin $(\mathrm{pmol} / \mathrm{l})$ & $75^{\mathrm{a}}$ & 9 & $84^{\mathrm{a}}$ & 9 & $55^{\mathrm{b}}$ & 3 \\
\hline GSIS $(\%)+$ & $100^{a}$ & 9 & $88^{a, b}$ & 6 & $70^{\mathrm{b}}$ & 9 \\
\hline
\end{tabular}

TBARS, thiobarbituric acid-reactive substances; AUC, area under the curve; OGTT, oral glucose tolerance test; GSIS, glucose-stimulated insulin secretion.

${ }^{a, b}$ Mean values within a row with unlike superscript letters were significantly different $(P<0.05$; one-way ANOVA and Duncan's multiple range test).

${ }^{*}$ AUC for blood glucose over $2 \mathrm{~h}$ in the OGTT ( $1.5 \mathrm{~g} / \mathrm{kg}$ of body weight).

† GSIS was measured by incubating isolated islets with $20 \mathrm{~mm}$-glucose for $10 \mathrm{~min}$. The insulin released per islet is expressed as a percentage of that in the LF group, assigned as $100 \%$. 
(A)
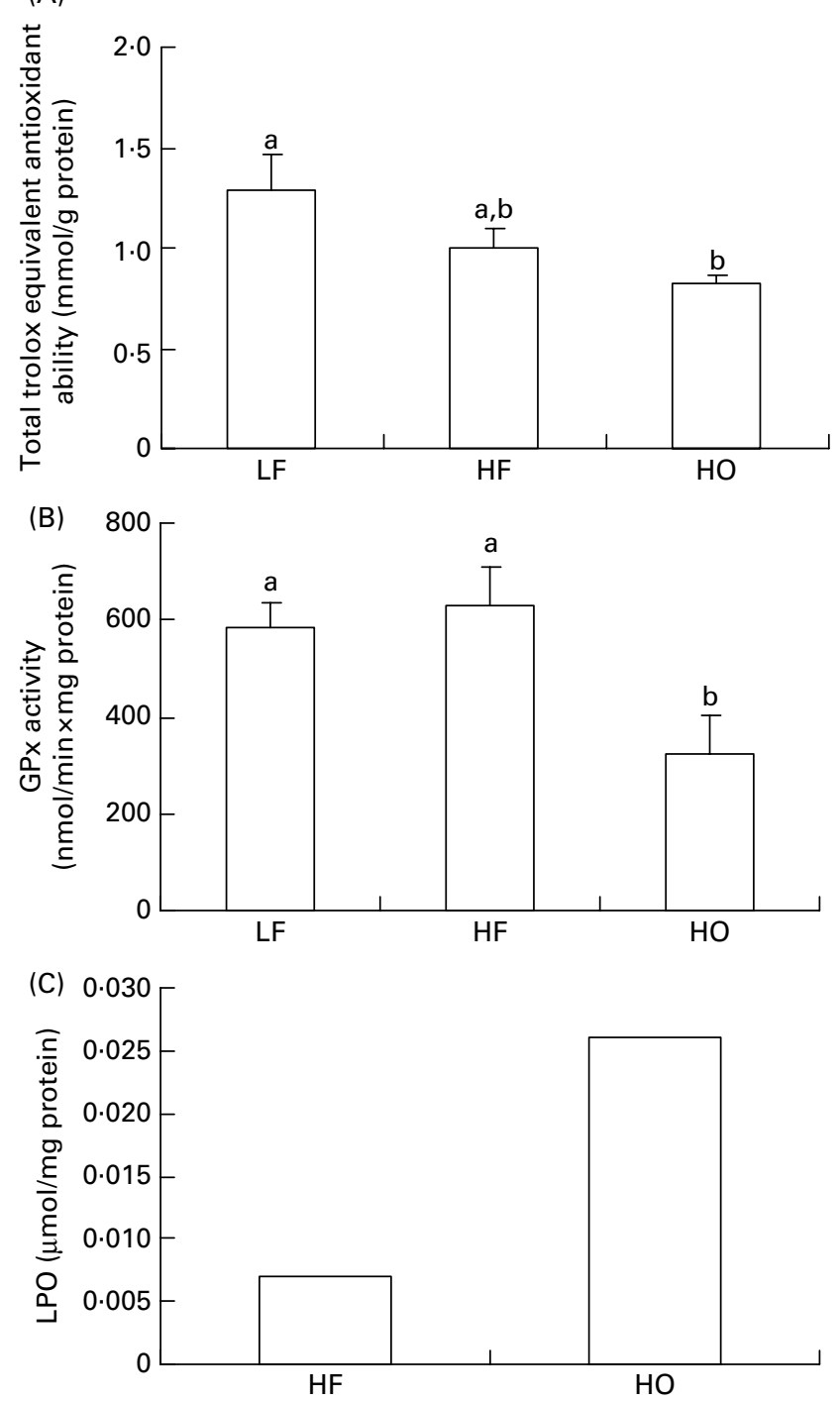

Fig. 1. Total antioxidant ability (A), glutathione peroxidase (GPx) activity (B) and lipid hydroperoxide (LPO) content (C) in the pancreatic islets of mice fed a low-fat basal diet containing $5 \mathrm{~g} / 100 \mathrm{~g}$ of fresh soyabean oil (LF group) or a high-fat diet containing $20 \mathrm{~g} / 100 \mathrm{~g}$ of either fresh soyabean oil (HF group) or OFO (HO group). In (A) and (B), values are means, with their standard errors represented by vertical bars $(n 8)$. ${ }^{\mathrm{a}, \mathrm{b}}$ Mean values with unlike letters were significantly different $(P<0 \cdot 05$; one-way ANOVA and Duncan's multiple range test). In (C), pooled samples were used.

in the HO-group islets compared with islets from the other two groups ( $P<0.05$; HO group $v$. LF and HF groups).

Finally, we tested whether vitamin E supplementation could prevent the adverse outcomes seen in the HO group. A depletion of tissue vitamin $\mathrm{E}$ caused by dietary OFO was seen in the serum, liver and pancreas (Table 3). Large-dose vitamin $\mathrm{E}$ supplementation resulted in a vitamin $\mathrm{E}$ status in the liver and serum in $\mathrm{HO}+\mathrm{E}$ group even higher than that in the HF group and increased levels in the pancreas compared with those seen in the HF group. Since the vitamin E concentrations vary with the lipid content ${ }^{(33)}$, vitamin $\mathrm{E}$ levels in the liver and serum were corrected by the TAG content, but the results were the same (pancreas vitamin E levels could not be corrected by the TAG content due to the limited sample size). In the $\mathrm{HO}+\mathrm{E}$ group, the levels of glucose tolerance, serum insulin and GSIS were similar to those in the HF group (Table 3).

During the GSIS analysis, we observed that the islets in the HO group were smaller and fragile and therefore compared islet morphology in the $\mathrm{HF}, \mathrm{HO}$ and $\mathrm{HO}+\mathrm{E}$ groups. Immunostaining for insulin (Fig. 4(A)) showed that the pancreatic islets in the HO group were smaller than those in the HF and $\mathrm{HO}+\mathrm{E}$ groups and irregular in shape, in contrast to the spherical shape seen in the other two groups. Islet size (sectional area) in the HO group was only one-third of that in the HF group and, although vitamin E supplementation significantly attenuated the reduction in islet size caused by OFO, islet size in the $\mathrm{HO}+\mathrm{E}$ group was still significantly smaller than that in the HF group (Fig. 4(B)).

\section{Discussion}

In contrast to the effect of an OFO-containing diet on lipid metabolism $^{(4-8)}$, the effect of such a diet on glucose metabolism has received little attention. We were the first to report that, in rodents, a high-OFO diet is less adipogenic than a diet containing the same amount of fresh soyabean oil, but causes glucose intolerance ${ }^{(9)}$. In a further study, we showed that the glucose intolerance elicited by dietary OFO is due to the impairment of insulin secretion, rather than peripheral insulin resistance ${ }^{(10)}$. In the present study, we demonstrated that dietary $\mathrm{OFO}$ ingestion, by depleting tissue vitamin $\mathrm{E}$, causes oxidative stress in pancreatic islets, thus compromising insulin secretion by lowering the mitochondrial membrane potential and decreasing insulin synthesis through the

(A)

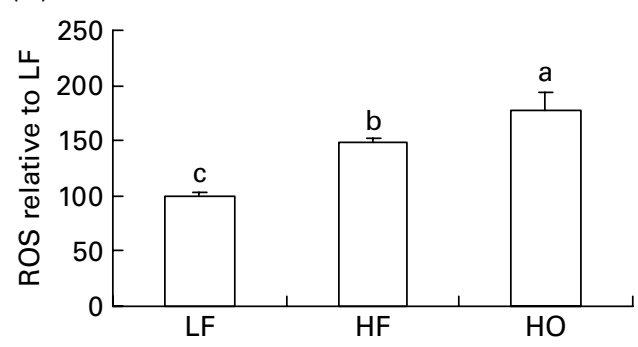

(B)
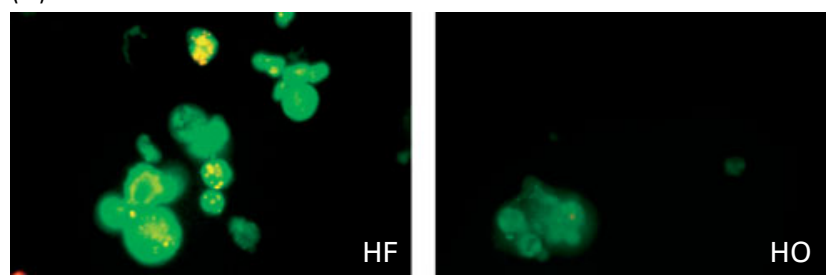

Fig. 2. Reactive oxygen species (ROS) levels (A) and mitochondrial membrane potential $(B)$ in the pancreatic islets of mice fed a low-fat basal diet containing $5 \mathrm{~g} / 100 \mathrm{~g}$ of fresh soyabean oil (LF group) or a high-fat diet containing $20 \mathrm{~g} / 100 \mathrm{~g}$ of either fresh soyabean oil (HF group) or OFO ( $\mathrm{HO}$ group). In $(\mathrm{A})$, values are means, with their standard errors represented by vertical bars $(n 5)$. ${ }^{a, b, c}$ Mean values with unlike letters were significantly different $(P<0.05$; one-way ANOVA and Duncan's multiple range test). In (B), representative images for the HF and $\mathrm{HO}$ groups are shown. 

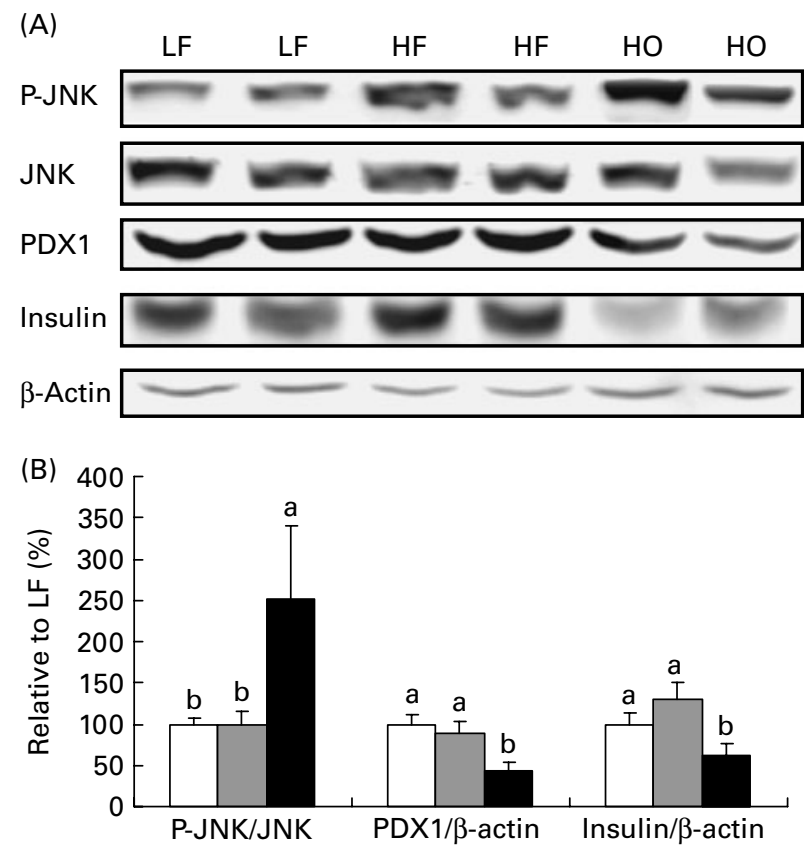

Fig. 3. Protein levels of phosphorylated c-Jun $\mathrm{NH}_{2}$-terminal kinase (JNK), pancreatic and duodenal homeobox factor-1 (PDX1) and insulin in the pancreatic islets of mice fed a low-fat basal diet containing $5 \mathrm{~g} / 100 \mathrm{~g}$ of fresh soyabean oil (LF group) or a high-fat diet containing $20 \mathrm{~g} / 100 \mathrm{~g}$ of either fresh soyabean oil (HF group) or OFO (HO group). The representative immunoblot (A) and the result of the image analysis (B) are shown. The value for the LF group was taken as $100 \%$. Values are means, with their standard errors represented by vertical bars $(n 8)$. ${ }^{\mathrm{a}, \mathrm{b}}$ Mean values with unlike letters were significantly different $(P<0.05$; one-way ANOVA and Duncan's multiple range test). $\square, \mathrm{LF} ; \square, \mathrm{HF} ; \mathbf{\square}, \mathrm{HO}$.

activation of JNK coupled with an inactivated PDX1 pathway. When the OFO-induced decrease in tissue vitamin $\mathrm{E}$ was prevented by large-dose oral vitamin E supplementation, the OFO-mediated impairment of glucose tolerance and insulin secretion was prevented, and the function was maintained at levels equivalent to those in the HF group. In addition, the OFO-mediated reduction in $\beta$-cell mass was also attenuated.
One possible concern about the present study could be that, since fresh soyabean oil contains abundant amounts of vitamin E (especially in the $\boldsymbol{\gamma}$-tocopherol form), which is destroyed during the deep-frying process ${ }^{(11)}$, there might be differences in the vitamin $\mathrm{E}$ content of the three experimental diets (LF, HF and HO), making the interpretation of the results difficult. However, as shown in Table 1, the vitamin E content of the HF diet was actually slightly higher than those in the other two diets, and the $\mathrm{HO}$ diet contained the same amount of vitamin $\mathrm{E}$ as the LF diet (all meeting the recommended vitamin $\mathrm{E}$ requirements in AIN-93, i.e. $75 \mathrm{IU}(0 \cdot 16$ $\mathrm{mmol}$ all-rac- $\alpha$-tocopherol acetate) $/ \mathrm{kg}$ diet). However, only the HO group suffered oxidative stress, as indicated by the liver vitamin $\mathrm{E}$ and thiobarbituric acid-reactive substance levels, and the HO group was the only group with impaired glucose tolerance. Based on the lack of any difference in tissue vitamin E content and glucose tolerance between the LF and HF groups, the HF group was assumed to be normal, and some comparisons were therefore made directly between the HF and HO groups (Table 3).

Dietary OFO-induced oxidative stress and OFOcompromised tissue vitamin $\mathrm{E}$ retention have been extensively studied $^{(11-13,34)}$. In the present study, for oral supplementation, we used a level of all-rac- $\alpha$-tocopherol acetate (i.e. $500 \mathrm{IU} / \mathrm{kg}$ diet) 6.6-fold higher than the AIN-93 recommendation level ${ }^{(35)}$. This dose has been shown to successfully prevent the reduction in $\alpha$-tocopherol and the increase in thiobarbituric acid-reactive substances in the tissues of rats fed the OFO $\operatorname{diet}^{(11)}$. Pancreas $\alpha$-tocopherol levels in OFO-fed animals had not previously been tested, and the results showed that this dose was also sufficient to maintain $\alpha$-tocopherol levels in the pancreas, but not as efficiently as in the liver or serum (Table 3). This might be attributed to a lower uptake or increased consumption of $\alpha$-tocopherol in pancreatic cells.

Similar to the present findings, Tsujinaka et al. ${ }^{(36)}$ reported that hydroperoxide from a dietary origin contributes to islet dysfunction. Using an air-dried vitamin E-stripped chow diet

Table 3. Vitamin E status, glucose tolerance and insulin secretion of mice fed a high-fat diet containing fresh soyabean oil (HF group) or oxidised frying oil without or with vitamin E supplementation ( $\mathrm{HO}$ and $\mathrm{HO}+\mathrm{E}$ groups, respectively)

(Mean values with their standard errors)

\begin{tabular}{|c|c|c|c|c|c|c|}
\hline & \multicolumn{2}{|c|}{$\mathrm{HF}$} & \multicolumn{2}{|c|}{$\mathrm{HO}$} & \multicolumn{2}{|c|}{$\mathrm{HO}+\mathrm{E}$} \\
\hline & Mean & SEM & Mean & SEM & Mean & SEM \\
\hline \multicolumn{7}{|l|}{ Vitamin E status } \\
\hline Serum $\alpha$-tocopherol $(\mu \mathrm{mol} / \mathrm{l})$ & $7 \cdot 60^{\mathrm{b}}$ & 1.25 & $4.06^{\mathrm{c}}$ & 0.74 & $9 \cdot 24^{\mathrm{a}}$ & $1 \cdot 18$ \\
\hline Liver $\alpha$-tocopherol (nmol/g) & $24 \cdot 7^{\mathrm{b}}$ & 4.7 & $8.85^{\mathrm{C}}$ & 2.66 & $46 \cdot 5^{a}$ & 10.9 \\
\hline Pancreas $\alpha$-tocopherol (nmol/g) & $13 \cdot 6^{\mathrm{a}}$ & $2 \cdot 0$ & $3.99^{b}$ & $0 \cdot 1$ & $10 \cdot 3^{a}$ & 1.1 \\
\hline \multicolumn{7}{|l|}{ Vitamin E status corrected by TAG } \\
\hline Serum $\alpha$-tocopherol ( $\mu \mathrm{mol} / \mathrm{g}$ TAG) & $1.47^{\mathrm{b}}$ & 0.20 & $1.14^{\mathrm{C}}$ & $0 \cdot 10$ & $2 \cdot 80^{\mathrm{a}}$ & 0.42 \\
\hline Liver $\alpha$-tocopherol (nmol/g TAG) & $4 \cdot 39^{b}$ & 0.89 & $1.86^{\mathrm{c}}$ & 0.24 & $9 \cdot 19^{\mathrm{a}}$ & 0.86 \\
\hline \multicolumn{7}{|l|}{ Glucose tolerance and insulin secretion } \\
\hline AUC in the OGTT $(\mathrm{mmol} \times \mathrm{min} /)^{*}$ & $1273^{\mathrm{b}}$ & 56 & $1676^{\mathrm{a}}$ & 143 & $1323^{b}$ & 48 \\
\hline Fasting serum insulin (pmol/l) & $222^{a}$ & 20 & $91.9^{b}$ & $21 \cdot 8$ & $184^{\mathrm{a}}$ & 12 \\
\hline GSIS (\%)† & $100^{\mathrm{a}}$ & 3.3 & $77^{\mathrm{b}}$ & 3.5 & $105^{a}$ & 20 \\
\hline
\end{tabular}

AUC, area under the curve; OGTT, oral glucose tolerance test; GSIS, glucose-stimulated insulin secretion.

a,b,c Mean values within a row with unlike superscript letters were significantly different $(P<0.05$; one-way ANOVA and Duncan's multiple range test).

${ }^{*}$ AUC for blood glucose over $2 \mathrm{~h}$ in the oral glucose $(1.5 \mathrm{~g} / \mathrm{kg}$ of body weight) tolerance test (OGTT).

† The GSIS was measured by incubating isolated islets with $20 \mathrm{~mm}$-glucose for $10 \mathrm{~min}$. The insulin released per islet is expressed as a percentage of that in the LF group, assigned as $100 \%$. 
(A)

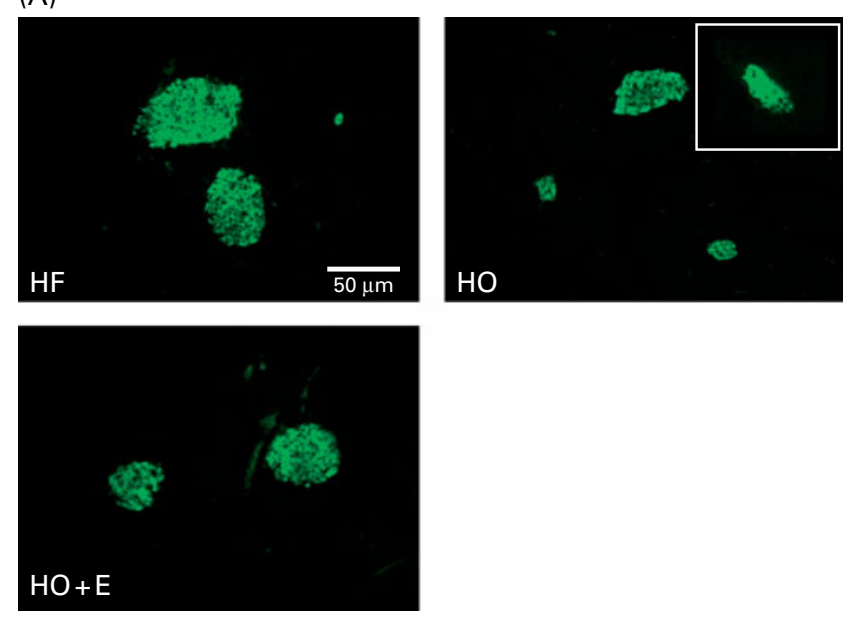

(B)

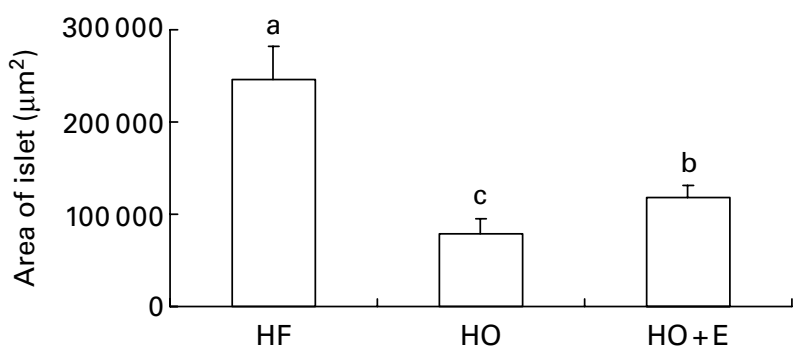

Fig. 4. Immunohistochemical analysis of islet morphology in mice fed a highfat diet containing fresh soyabean oil (HF group) or oxidised frying oil without or with vitamin $\mathrm{E}$ supplementation ( $\mathrm{HO}$ and $\mathrm{HO}+\mathrm{E}$ groups, respectively). The $\beta$-cells were immunostained for insulin $(A)$, and islet size was quantified for the area containing cells positive for insulin (B). Values are means, with their standard errors represented by vertical bars (three mice in each group and fifty islets per mouse). ${ }^{a, b, c}$ Mean values with unlike letters were significantly different $(P<0.05$; one-way ANOVA and Duncan's multiple range test).

(containing autoxidative lipids), they showed that a diet high in LPO results in an increased LPO content in tissues and glucose intolerance in Sprague-Dawley rats ${ }^{(36)}$. Glucose intolerance was associated with the development of both insulin resistance and an inability to secrete insulin. In response to oxidative stress, activation of a NF- $\mathrm{B}$ signalling pathway in islet cells from LPO-fed rats was observed. In our OFO model, impairment of insulin secretion, but not of insulin sensitivity, has been observed ${ }^{(9,10)}$. One difference between the study of Tsujinaka and the present study was that the OFO used in the present study was much lower in LPO than the autoxidative lipids used by Tsujinaka ${ }^{(4,11,36)}$. During the deep-frying process, LPO, the primary oxidative product, is volatilised or decomposed into secondary products at this high temperature ${ }^{(1)}$. Thus, the accumulation of LPO in the tissues of OFO-fed mice in the present study was attributed to endogenous production due to a lower free-radical scavenging ability. However, a compromised vitamin E status was seen in both studies and might be the cause of deterioration in glucose metabolism.

The present study is the first to evaluate the free-radical scavenging ability of islets in OFO-fed mice. In parallel with vitamin E depletion, the reduced total antioxidant ability and GPX activity and the higher LPO and ROS content in the HO group indicate that the OFO-exposed islets were subjected to greater oxidative stress. ROS have been shown to be involved in pancreatic $\beta$-cell dysfunction and apoptosis in a rodent model of type 1 diabetes $^{(16-19)}$ and in the failure of the first phase of GSIS in type 2 diabetes ${ }^{(20)}$. Histological analyses of pancreatic islets in the $\mathrm{HO}$ group showed that islet size was markedly reduced compared with its high-fat counterpart (i.e. HF group) and was partially prevented by vitamin $\mathrm{E}$ supplementation. The reduction in $\beta$-cell mass might be due to the increased apoptosis or decreased proliferation of $\beta$-cells. ROS-mediated $\beta$-cell death has been shown to be regulated by interactions between stress-activated protein kinases through phosphorylation/dephosphorylation cascades, which result in sustained JNK activation, thus leading to cell apoptosis ${ }^{(37)}$. Although apoptosis of $\beta$-cells was not examined in the present study, increased ROS production and JNK activation were seen in the islets from the HO group.

The decreased $\Delta \Psi_{\mathrm{m}}$ and GSIS in the islets of OFO-fed mice indicate that the mitochondria were also subjected to ROS-induced damage, which interrupts the signal transduction normally coupling glucose metabolism to insulin secretion. The expression and function of uncoupling protein 2 has been shown to be increased by ROS superoxide ${ }^{(38)}$. In addition, induction of uncoupling protein 2 mRNA in $\beta$-cells is stimulated by fatty acid $\beta$-oxidation ${ }^{(39)}$. Although OFO-mediated PPAR $\alpha$ activation in pancreatic islets has never been studied, it is possible that dietary OFO increases fatty acid $\beta$-oxidation not only in the liver ${ }^{(4,7)}$, but also in other tissues, thus increasing uncoupling protein 2 expression in islets. Uncoupling protein 2 impairs GSIS by causing mitochondrial proton leakage and a consequent negative effect on ATP production ${ }^{(40)}$.

Although c-JNK, p38 MAPK and protein kinase C have been shown to be activated in islets subjected to oxidative stress, only JNK activation has been recognised as being responsible for the ROS-mediated down-regulation of insulin gene expression $^{(23,24)}$. JNK activation suppresses insulin expression by decreasing PDX1 levels and functions, such as DNAbinding activity or nuclear translocation ${ }^{(23,24)}$. In accordance with this notion, increased JNK phosphorylation, accompanied by reduced levels of PDX1 and insulin, in the islets of OFO-fed mice was seen in the present study. The down-regulation of insulin might be attributed to lower transcription factor PDX1 levels and activity. Several mechanisms have been postulated to explain the decrease in PDX1 levels due to oxidative stress. ROS can suppress $P D X 1$ transcription by inducing nuclear localisation of forkhead box O1 (an inhibitor of PDX1 transcription) ${ }^{(32)}$. Moreover, oxidative stress might affect PDX1 gene expression through acetylation of histones $\mathrm{H} 3$ and $\mathrm{H} 4$ bound to the PDX1 promoter ${ }^{(41)}$. It has also been reported that oxidative stress decreases PDX1 protein stability through phosphorylation by a glycogen synthase kinase 3-dependent pathway, leading to its degradation in the proteosome ${ }^{(42)}$

Currently, it is not known whether inflammation is involved in OFO-induced islet dysfunction. We have measured TNF- $\alpha$ protein levels in islets from fresh soyabean oil- or OFO-fed 
mice, but found no difference (data not shown). Since significantly higher levels of $\mathrm{PGE}_{2}$ metabolites have been observed in the plasma and urine of OFO-fed rats ${ }^{(43)}$ and increased $\mathrm{PGE}_{2}$ expression in islets has been shown to result in the destruction of pancreatic islets ${ }^{(44)}$. The effect of oxidative stress, inflammation and apoptosis on $\beta$-cells and OFOinduced islet dysfunction awaits further study.

In conclusion, the present study shows that a high level of ingestion of dietary OFO without additional vitamin $\mathrm{E}$ supplementation impairs glucose metabolism by causing oxidative damage to pancreatic islets. Increased ROS levels and a decreased free-radical scavenging ability were observed in islets of OFO-fed mice. The reduction in insulin secretion in the islets of OFO-fed mice was associated with a lower mitochondrial membrane potential, and the reduced insulin synthesis was associated with JNK activation coupled to a reduction in PDX1 levels. OFO-mediated islet dysfunction is caused by vitamin E deficiency, which is secondary to OFO ingestion, since supplementation with vitamin $\mathrm{E}$ can prevent these adverse effects on glucose metabolism.

\section{Acknowledgements}

The present study was financially supported by grants from the National Science Council (NSC98-2320-B-039-039-MY3), Taiwan. We thank J. H. Juang for the technical assistance in islet isolation. The authors declare that there are no conflicts of interest. P.-M. C. designed the study; Y.-F. C., H.-M. S., M.-F. Y., C.-Y. H., and C.-H. H. conducted the study; Y.-F. C. and H.-M. S. analysed the data; P.-M. C. wrote the manuscript and had primary responsibility for the final content. All authors read and approved the final manuscript.

\section{References}

1. Chang SS, Peterson RJ \& Ho CT (1978) Chemical reactions involved in the deep-fat frying of foods. $\mathrm{J} \mathrm{Am} \mathrm{Oil} \mathrm{Chem}$ Soc 55, 718-727.

2. Huang CJ, Cheung NS \& Lu VR (1988) Effects of deteriorated frying oil and dietary protein levels on liver microsomal enzymes in rats. J Am Oil Chem Soc 65, 1796-1803.

3. Gonzáles-Muñoz MJ, Bastida S \& Sánchez-Muniz FJ (1998) Short term in vivo digestibility of triglyceride polymers, dimmers, and monomers of thermoxidized palm olein used in deep-frying. J Agric Food Chem 46, 5188-5193.

4. Chao PM, Chao CY, Lin FJ, et al. (2001) Oxidized frying oil up-regulates hepatic acyl-CoA oxidase and cytochrome $\mathrm{P} 4504 \mathrm{~A} 1$ genes in rats and activates PPAR $\alpha$. J Nutr 131, 3166-3174.

5. Chao PM, Hsu SC, Lin FJ, et al. (2004) The up-regulation of hepatic acyl-CoA oxidase and cytochrome P450 4A1 mRNA expression by dietary oxidized frying oil is comparable between male and female rats. Lipids 39, 233-238.

6. Chao PM, Yang MF, Tseng YN, et al. (2005) Peroxisome proliferation in liver of rats fed oxidized frying oil. $J$ Nutr Sci Vitaminol 51, 361-368.

7. Sulzle A, Hirche F \& Eder K (2004) Thermally oxidized dietary fat upregulates the expression of target genes of PPAR $\alpha$ in rat liver. J Nutr 134, 1375-1383.
8. Eder K, Suelzle A, Skufca P, et al. (2003) Effects of dietary thermoxidized fats on expression and activities of hepatic lipogenic enzymes in rats. Lipids $\mathbf{3 8}, 31-38$

9. Chao PM, Huang HL, Liao CH, et al. (2007) A high oxidised frying oil content diet is less adipogenic, but induces glucose intolerance in rodents. Br J Nutr 98, 63-71.

10. Liao CH, Shaw HM \& Chao PM (2008) Impairment of glucose metabolism in mice induced by dietary oxidized frying oil is different from that induced by conjugated linoleic acid. Nutrition 24, 744-752.

11. Liu JF \& Huang CJ (1995) Tissue $\alpha$-tocopherol retention in male rats is compromised by feeding diets containing oxidized frying oil. J Nutr 125, 3071-3080.

12. Liu JF \& Huang CJ (1996) Dietary oxidized frying oil enhances tissue $\alpha$-tocopherol depletion and radioisotope tracer excretion in vitamin E-deficient rats. J Nutr 126, 2227-2235.

13. Huang WC, Kang ZC, Li YJ, et al. (2009) Effects of oxidized frying oil on proteins related to $\alpha$-tocopherol metabolism in rat liver. J Clin Biochem Nutr 45, 20-28.

14. Lenzen S, Drinkgern J \& Tiedge M (1996) Low antioxidant enzyme gene expression in pancreatic islets compared with various other mouse tissues. Free Radic Biol Med 20, 463-466.

15. Sigfrid LA, Cunningham JM, Beeharry N, et al. (2004) Antioxidant enzyme activity and mRNA expression in the islets of Langerhans from the $\mathrm{BB} / \mathrm{S}$ rat model of type 1 diabetes and an insulin-producing cell line. J Mol Med $\mathbf{8 2}$, $325-335$.

16. Kaneto H, Fujii J, Myint T, et al. (1996) Reducing sugars trigger oxidative modification and apoptosis in pancreatic betacells by provoking oxidative stress through the glycation reaction. Biochem J 320, 855-863.

17. Kaneto H, Kajimoto Y, Fujitani Y, et al. (1999) Oxidative stress induces p21 expression in pancreatic islet cells: possible implication in beta-cell dysfunction. Diabetologia $\mathbf{4 2}$, 1093-1097.

18. Maechler P, Jornot L \& Wollheim CB (1999) Hydrogen peroxide alters mitochondrial activation and insulin secretion in pancreatic beta cells. J Biol Chem 274, 27905-27913.

19. Sakai K, Matsumoto K, Nishikawa T, et al. (2003) Mitochondrial reactive oxygen species reduce insulin secretion by pancreatic beta-cells. Biochem Biophys Res Commun 300, 216-222.

20. Robertson RP (2006) Oxidative stress and impaired insulin secretion in type 2 diabetes. Curr Opin Pharmacol 6, 615-619.

21. Ahlgren U, Jonsson J, Jonsson L, et al. (1998) Beta-cellspecific inactivation of the mouse Ipf1/Pdx1 gene results in loss of the beta-cell phenotype and maturity onset diabetes. Genes Dev 12, 1763-1768.

22. Matsuoka T, Kajimoto Y, Watada H, et al. (1997) Glycationdependent, reactive oxygen species-mediated suppression of the insulin gene promoter activity in HIT cells. $J$ Clin Invest 99, 144-150.

23. Kaneto H, Xu G, Fujii N, et al. (2002) Involvement of c-Jun N-terminal kinase in oxidative stress-mediated suppression of insulin gene expression. J Biol Chem 277, 30010-30018.

24. Kawamori D, Kajimoto Y, Kaneto H, et al. (2003) Oxidative stress induces nucleo-cytoplasmic translocation of pancreatic transcription factor PDX-1 through activation of c-Jun $\mathrm{NH}_{2}$-terminal kinase. Diabetes 52, 2896-2904.

25. Kaneto H, Matsuoka TA, Nakatani Y, et al. (2005) Oxidative stress and the JNK pathway in diabetes. Curr Diabetes Rev $\mathbf{1}$, 65-72.

26. Lacy PE \& Kostianovsky M (1967) Method for the isolation of intact islets of Langerhans from the rat pancreas. Diabetes 16, 35-39. 
27. Gotoh M, Maki T, Satomi S, et al. (1987) Reproducible high yield of rat islets by stationary in vitro digestion following pancreatic ductal or portal venous collagenase injection. Transplantation 43, 725-730.

28. Oteiza PI, Olin KL, Fraga CG, et al. (1995) Zinc deficiency causes oxidative damage to proteins, lipids and DNA in rat testes. J Nutr 125, 823-829.

29. Cossarizza A, Baccarani-Contri M, Kalashnikova G, et al. (1993) A new method for the cytofluorimetric analysis of mitochondrial membrane potential using the J-aggregate forming lipophilic cation 5,5',6,6'-tetrachloro-1,1',3,3'-tetraethylbenzimidazolcarbocyanine iodide (JC-1). Biochem Biophys Res Commun 197, 40-45.

30. Xie Z, Kometiani P, Liu J, et al. (1999) Intracellular reactive oxygen species mediate the linkage of $\mathrm{Na}^{+} / \mathrm{K}^{+}$-ATPase to hypertrophy and its marker genes in cardiac myocytes. J Biol Chem 274, 19323-19328.

31. Heart E, Corkey RF, Wikstrom JD, et al. (2006) Glucosedependent increase in mitochondrial membrane potential, but not cytoplasmic calcium, correlates with insulin secretion in single islet cells. Am J Physiol Endocrinol Metab 290, E143-E148.

32. Kawamori D, Kaneto H, Nakatani Y, et al. (2006) The forkhead transcription factor Foxo1 bridges the JNK pathway and the transcription factor PDX-1 through its intracellular translocation. J Biol Chem 281, 1091-1098.

33. Kappus H \& Diplock AT (1992) Tolerance and safety of vitamin E: a toxicological position report. Free Radic Biol Med 13, 55-74.

34. Izaki Y, Yoshikawa S \& Uchiyama M (1984) Effect of ingestion of thermally oxidized frying oil on peroxidative criteria in rats. Lipids 19, 324-331.

35. Reeves PG, Nielsen FH \& Fahey GC (1993) AIN-93 purified diets for laboratory rodents: final report of the American Institute of Nutrition ad hoc writing committee on the reformulation of the AIN-76A rodent diet. J Nutr 123, 1939-1951.
36. Tsujinaka K, Nakamura T, Maegawa H, et al. (2005) Diet high in lipid hydroperoxide by vitamin E deficiency induces insulin resistance and impaired insulin secretion in normal rats. Diabetes Res Clin Pract 67, 99-109.

37. Hou N, Torii S, Saito N, et al. (2008) Reactive oxygen species-mediated pancreatic beta-cell death is regulated by interactions between stress-activated protein kinases, p38 and c-Jun N-terminal kinase, and mitogen-activated protein kinase phosphatases. Endocrinology 149, 1654-1665.

38. Echtay KS, Roussel D, St-Pierre J, et al. (2002) Superoxide activates mitochondrial uncoupling proteins. Nature $\mathbf{4 1 5}$ 96-99.

39. Li LX, Skorpen F, Egeberg K, et al. (2002) Induction of uncoupling protein 2 mRNA in beta-cells is stimulated by oxidation of fatty acids but not by nutrient oversupply. Endocrinology 143, 1371-1377.

40. Krauss S, Zhang CY, Scorrano L, et al. (2003) Superoxidemediated activation of uncoupling protein 2 causes pancreatic beta cell dysfunction. J Clin Invest 112, 1831-1842.

41. Wang XD, Vatamaniuk MZ, Wang SK, et al. (2008) Molecular mechanisms for hyperinsulinaemia induced by overproduction of selenium-dependent glutathione peroxidase- 1 in mice. Diabetologia 51, 1515-1524.

42. Boucher MJ, Selander L, Carlsson L, et al. (2006) Phosphorylation marks IPF1/PDX1 protein for degradation by glycogen synthase kinase 3-dependent mechanisms. J Biol Chem $\mathbf{2 8 1}$, 6395-6403.

43. Huang C (2003) Prostaglandin formation as affected by dietary frying oil and other food components. In Essential Fatty Acids and Eicosanoids : Invited Papers from the Fifth International Congress, pp. 132-140. Urbana, IL: AOCS Press.

44. Oshima H, Taketo MM \& Oshima M (2006) Destruction of pancreatic beta-cells by transgenic induction of prostaglandin $\mathrm{E}_{2}$ in the islets. J Biol Chem 281, 29330-29336. 